\title{
The underground industry of wastewater adulteration: how to trick legal testing with COD removers
}

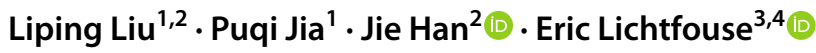

Published online: 8 July 2021

(c) The Author(s), under exclusive licence to Springer Nature Switzerland AG 2021

\begin{abstract}
Adulteration is an illegal practice often committed in food and cosmetic industries, yet rarely in environmental regulation compliance. The Chinese Ministry of Ecology and Environment recently issued a law prohibiting any intentional use of 'interfering agents' during wastewater compliance testing. For the first time, such illegal practices are brought to public attention, though they have been barely discussed previously in the scientific literature. The fraudulent method involves the addition into wastewater of a sodium chlorate-based compound, named 'COD remover,' which artificially decreases the chemical oxygen demand (COD) measured during legal testing using the dichromate method. Such practices can decrease COD from $214 \mathrm{mg} / \mathrm{L}$ to below $100 \mathrm{mg} / \mathrm{L}$. COD removers are designed to work under testing conditions, and they do not effectively purify wastewater. The use of COD removers has created an underground industry, where users can anonymously purchase those products in 25-kg packages from all major domestic online retailers in China. A notable case was recently publicized after the new legislation, where 131 tons of COD remover had been used in a municipal wastewater treatment plant. Nonetheless, very little is known about other possible cases in China and elsewhere, and whether COD is the sole target of fraudulent practice in wastewater testing. For instance, nitrites could be used as interfering agents in the iodometric method for measuring dissolved oxygen in water and wastewater. There are also reports of chemical adulteration in online monitoring of gas emissions. Since targeted chemical adulteration is based on the knowledge of reactions and mechanisms of testing methods, there is a need to develop more robust and adulteration-proof methods for wastewater testing.
\end{abstract}

Keywords Chemical oxygen demand $\cdot$ Effluent discharge $\cdot$ Sodium chlorate $\cdot$ Interfering agent $\cdot$ Dissolved oxygen . Iodometric method

On December 14, 2020, the Ministry of Ecology and Environment of China (MEEC) introduced a new legislative

Puqi Jia

jpq@1zu.edu.cn

$\triangle$ Jie Han

jiehan@xjtu.edu.cn

1 Department of Environmental Science and Engineering, College of Earth and Environmental Sciences, Lanzhou University, Lanzhou 730000, People's Republic of China

2 Institute of Global Environmental Change, School of Human Settlements and Civil Engineering, Xi' an Jiaotong University, Xi'an 710049, People's Republic of China

3 CNRS, IRD, INRAE, Coll France, CEREGE, Aix-Marseille University, 13100 Aix en Provence, France

4 State Key Laboratory of Multiphase Flow in Power Engineering, Xi' an Jiaotong University, Xi' an 710049, Shaanxi, People's Republic of China framework for treatment and management of urban wastewater. For the first time, the intentional use of chemical reagents as interfering agents for manipulation of monitoring data during wastewater compliance testing is deemed illegal (MEEC 2020a). One month later, the Ministry disclosed an investigation at a municipal wastewater treatment plant where operators routinely used a 'COD remover' as a chemical adulterant to interfere with the compliance testing of wastewater effluent quality. This is the first legal action taken against such practices in the nation under the new legislation (MEEC 2021). The underground industry of compliancetargeted wastewater chemical adulteration has surfaced to public attention (Fig. 1). 


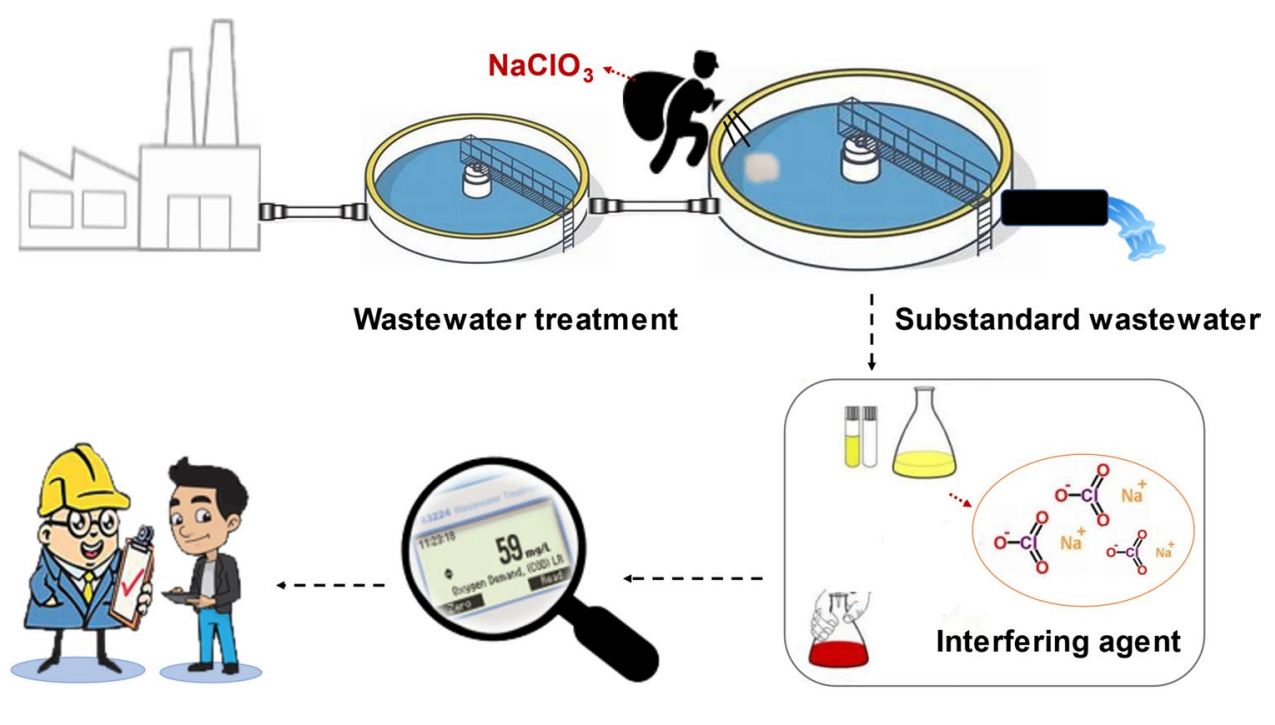

Supervisor

Standard

Wastewater compliance testing

Fig. 1 Chemical adulteration in wastewater compliance testing. By targeting the official dichromate method used for compliance testing of wastewater effluents, the addition of the sodium chlorate $\left(\mathrm{NaClO}_{3}\right)$-based 'COD remover' artificially reduces the chemical oxygen demand (COD) results by oxidizing reactive organic matter in wastewater samples at testing conditions. Similarly, nitrites are

\section{Testing chemical oxygen demand prevents pollution of ecosystems}

The chemical oxygen demand (COD) is one of the most widely used indicators of the loading of oxidizable organic matter and pollutants in wastewater (Páramo et al. 2016; Yang et al. 2018; BS 1988; DIN 1986; EPA 1993; ISO 1989, 2002; MEEC 2017a, b; UNE 2002). COD monitoring thus allows to prevent pollution of rivers and ecosystems by excessive organic matter and associated contaminants. For instance, for most types of industrial wastewaters in China, the maximum limit of COD level is $50-150 \mathrm{mg} / \mathrm{L}$ allowed for the discharge of treated effluents (MEEC 2011, 2012, 2020b). Specifically, the dichromate method is common for measuring COD levels in wastewater due to its ability to degrade a wide range of organic pollutants (Zhao et al. 2004). The dichromate method is also the current standard testing method specified by various authorities and organizations including the US EPA (Method 410.4, Rev 2.0, EPA 1993), the MEEC (HJ 828-2017 and HJ 924-2017, MEEC 2017a, b), the International Organization for Standardization (ISO 6060:1989 and ISO 15,705:2002, ISO 1989, 2002), the British Standards Institution (BS 6068-2.34:1988, BS 1988), the German Institute for Standardization (DIN 38,414-9:1986, DIN 1986), and the Una Norma Espanola (UNE 77,004:2002, Una Norma Espanola 2002). However, used as interfering agents in the iodometric method, which is used for measuring dissolved oxygen levels in water and wastewater. While enforceable quality standards are an essential part of environmental waste management, the specific reactions and mechanisms used in compliance testing methods provide inherent vulnerability for targeted chemical adulteration

chemical adulterants can be illegally used when the COD level of the discharged effluent does not meet the current quality standards.

\section{Principles of wastewater adulteration}

Currently known practices of chemical adulteration in wastewater compliance testing mainly involve the use of a chemical product ambiguously labeled as 'COD remover,' which can be added into treated wastewater effluents at intermediate or the final stage of treatment that are to be sampled for compliance testing of COD levels. The product, which contains sodium chlorate $\left(\mathrm{NaClO}_{3}\right)$ as the main ingredient, lowers the COD values measured by the dichromate method during wastewater compliance testing (MEEC 2020b). By oxidizing organic pollutants in wastewater under standard testing conditions, e.g., $30 \mathrm{~min}$ acid digestion at $165^{\circ} \mathrm{C}$ (MEEC 2017a), sodium chlorate acts as an interfering agent in COD measurements under the current testing protocols. The following reactions take place in the presence of sodium chlorate under the testing conditions, where 'Organic' denotes organic pollutants present in wastewater samples and 'Organic-O' denotes degradation intermediates after oxidation. Specifically, (1)-(3) are reactions that occur during normal testing, involving oxidation of organics by dichromate, whereas (4) and (5) are induced by the addition of the COD remover, sodium chlorate. 


$$
4 \mathrm{Cl}^{-}+\mathrm{Hg}^{2+} \rightarrow \mathrm{HgCl}_{4}^{2-}
$$

$\mathrm{Cr}_{2} \mathrm{O}_{7}^{2-}+$ Organic $\rightarrow \mathrm{Cr}^{3+}+$ Organic-O $/ \mathrm{CO}_{2}$

$\mathrm{Cr}_{2} \mathrm{O}_{7}^{2-}+$ Organic-O $\rightarrow \mathrm{Cr}^{3+}+\mathrm{CO}_{2}$

$\mathrm{ClO}_{3}^{-}+$Organic $+\mathrm{H}_{2} \mathrm{SO}_{4} \rightarrow \mathrm{ClO}_{2}+\mathrm{H}\left(\mathrm{SO}_{4}\right)^{-}+$Organic-O $/ \mathrm{CO}_{2}$

$\mathrm{ClO}_{2}+$ Organic $\rightarrow$ Organic-O $+\mathrm{Cl}^{-}$

The presence of sodium chlorate can have dramatic influences on COD testing results in samples analyzed by the dichromate method. In the heated concentrated acid solutions during the digestion process, chlorate anions $\left(\mathrm{ClO}_{3}{ }^{-}\right)$ quickly undergo reduction and transform into chlorine dioxide $\left(\mathrm{ClO}_{2}\right)$, an oxidizing gas generated from reactions between $\mathrm{NaClO}_{3}$ and organic pollutants in the wastewater sample (Eq. (4), Deshwal and Lee 2004). Most organic substances, including persistent compounds, can be quickly oxidized by $\mathrm{ClO}_{2}$ (Huber et al. 2005; Singh et al. 2020; Sharma and Sohn 2012). The redox reactions initiated by $\mathrm{NaClO}_{3}$ and $\mathrm{ClO}_{2}$ therefore reduce the total consumption of dichromate anions $\left(\mathrm{Cr}_{2} \mathrm{O}_{7}{ }^{2-}\right)$ by organic matter present in the wastewater sample and subsequently lower the COD measurements using the dichromate method, under the test conditions. The experimental results on simulated wastewater samples using benzohydroxamic acid showed that the addition of $\mathrm{NaClO}_{3}$ consistently reduced COD measurements from $214 \mathrm{mg} / \mathrm{L}$ to below $100 \mathrm{mg} / \mathrm{L}$ using the dichromate method, when the concentration of $\mathrm{NaClO}_{3}$ reached $600 \mathrm{mg} / \mathrm{L}$ in the samples tested (Meng et al. 2019). COD reductions were only observed under the testing conditions, while the COD levels did not decrease under normal conditions such as the wastewater storage or treatment processes (Meng et al. 2019).

\section{Tons of COD removers}

In China, commercial products labeled as 'COD remover' with the appearances of white to pale yellow crystalline solids similar to that of sodium chlorate are often sold in bulk quantities, e.g., 25-kg bags, which can be purchased anonymously online. In fact, COD removers are available from individual sellers or retailers hosted in all major domestic e-commerce sites and mobile device apps (E-retailers 2021). Removers are often marketed without explicitly identifying their chemical contents to evade the oversight of regulatory authorities. Due to the ambiguous labeling and the strong oxidizing nature of sodium chlorate, it can be mistakenly used, which indeed caused a major explosion and fire in 2019 (DEMSP 2019). To date, there have been only two public reports on the use of COD removers in China. However, the manufacturing and use of COD removers are likely to have already created an underground industry with some companies routinely using removers for compliance purposes. This hypothesis is supported by product specifications, typically in $25-\mathrm{kg}$ packages, the large numbers of active sellers on e-commerce platforms, and the statistics on product transactions displayed by some retailers (E-retailers 2021). One case report even disclosed that the total amount of COD remover used by a contractor of a municipal wastewater treatment plant reached over 131,000 kg (MEEC 2021), while in another case a company received $2000 \mathrm{~kg}$ of COD remover in a single delivery, which are typical industrial amounts (DEMSP 2019).

\section{Only in China and only for COD? Other targets?}

These reports raise the natural question that whether such practices have only existed in China, given the fact that both COD measurement and the dichromate method are widely adopted by authorities as the standard protocols in wastewater compliance testing (BS 1988; DIN 1986; EPA 1993; ISO 1989, 2002; MEEC 2017a, b; Una Norma Espanola 2002). After all, the chemistry is incredibly straightforward and the reagent itself is cheap, accessible, and highly effective in lowering COD measurements under the testing conditions. Another question is whether COD measurement is the only target of chemical adulteration in wastewater testing. Indeed, other reactions, mechanisms, and parameters may have been also targeted to manipulate the testing data. For instance, several standards and protocols use the iodometric method to measure the dissolved oxygen level in water and wastewater, including the ISO 5813 standard (ISO 1983), the GB-7489 standard (MEEC 1987), and the Winkler method specified by the US EPA (EPA 1992). In these methods, sulfuric acid is added to dissolve manganese manganate precipitates and to form iodine, which is used as the indicator of dissolved oxygen levels in the samples. The presence of nitrite salts, however, increases the measurements on dissolved oxygen by releasing additional iodine and nitric oxide, after reacting with iodides (Lan et al. 2011). Moreover, cases of online monitoring devices being interfered to evade environmental regulation have also been reported. For instance, in 2017 a company in Zhejiang Province in China was found to intentionally feed lime-neutralized exhaust gas to reduce the concentrations of sulfur dioxide and nitrogen oxides measured in emissions by an automatic sampling and online monitoring device (China Court 2019). 
It is currently unknown whether there are other practices of chemical adulteration targeting quality indicators used in current compliance testing of wastewater effluents or exhaust gas emissions. To rule out the presence of interfering agents in samples, it may be necessary to conduct a screening test prior to adopting the standard testing protocols. In dichromate-based COD measurements, the presence of chlorates can be determined spectrophotometrically by ferric iron absorbance after their reduction by ferrous irons in sulfuric acid solutions (Prince 1964). Where available, new modified testing methods or multiple testing methods that are unrelated in their mechanisms may be specified by regulatory authorities for more robust compliance testing. The use of improved methods or the simultaneous use of two or more testing methods can significantly improve the confidence in testing results. For instance, the modified Winkler method with sodium azide can suppress interferences by nitrites present in samples which would react with iodide in iodometric measurements of dissolved oxygen in water and wastewater (NEMI 1997; Kuswandi et al. 2019). Alternatively, unrelated testing methods may also be used to check the dissolved oxygen levels measured in the same water or wastewater samples by the iodometric method (ISO 2012, 2014). In the long term, there is a need to improve treatment technologies (Lavanya et al. 2018) and develop more robust and adulteration-proof methods for environmental compliance testing and monitoring of water, wastewater effluents, and gas emissions.

Acknowledgements This work was funded by the Young Talent Support Plan of Xi' an Jiaotong University and the Research Startup Fund for Young Research Fellows of Lanzhou University (No. 504000-561119211).

\section{Declarations}

Conflict of interest The authors declare that they have no conflict of interest in this work.

\section{References}

British Standard (1988) Water quality-Physical, chemical, and biochemical methods-Method for the determination of the chemical oxygen demand (BS 6068-2.34(1988): 1988). https://infos tore.saiglobal.com/en-us/Standards/BS-6068-2-34-1988-1988245504_SAIG_BSI_BSI_571840/. (accessed 24 June 2021)

China Court (2019) Shaoxing Environmental Protection Bureau, Zhejiang Shangfeng Building Materials Co., Ltd., Zhuji City Ciwu Town People's Government ecological environmental damage compensation agreement judicial confirmation case. https://www. chinacourt.org/article/detail/2019/06/id/4004425.shtml. (accessed 24 June 2021)

Department of Emergency Management of Sichuan Province (DEMSP) (2019) Sichuan Yibin Hengda Technology Co, Ltd. reported the investigation of the 'July 12' major explosion and fire accident:
15 people were transferred to the judiciary, and 4 people were investigated by the Discipline Inspection Commission. https:// yjt.sc.gov.cn/scyjt/anquanyinhuanbaoguangtai/2019/12/6/048e3 1ab15664b86bdcdfafcde7ec0b4.shtml. (accessed 24 June 2021)

Deshwal BR, Lee HK (2004) Kinetics and mechanism of chloride based chlorine dioxide generation process from acidic sodium chlorate. J Hazard Mater 108(3):173-182. https://doi.org/10. 1016/j.jhazmat.2003.12.006

DIN (1986) German standard methods for the examination of water, waste water and sludge; sludge and sediments (group S); determination of the chemical oxygen demand (COD) (S 9) (DIN 38414-9: 1986-09). https://www.beuth.de/en/standard/din-384149/1310332. (accessed 24 June 2021)

E-retailers (2021) https://p4psearch.1688.com/p4p114/p4psearch/offer. $\mathrm{htm}$ ?keywords=COD\%E5\%8E\%BB\%E9\%99\%A4\%E5\%89\%82\& cosite $=$ baidujj_pz\&location $=$ re $\&$ trackid $=\% 7$ Btrackid $\% 7 D \&$ spm=a2609.11209760.j3f8podl.e5rt432e\&keywordid=\%7Bkey wordid\%7D; https://mobile.yangkeduo.com/goods.html?goods_ $\mathrm{id}=199144928515 \&$ page_from $=23 \& \mathrm{pxq} \_$secret_key $=5 \mathrm{BANQ}$ LKBRTLB2LSLI5RKPHIGODDPCZZFURMLGBIPADWDH T66HABQ\&share_uin=3R22JUWR2ZOL5BLRPIY3DS6UFQ_ GEXDA\&refer_share_id=a6acfad5575346158ce11addb2423d $06 \&$ refer_share_uid $=1788562149 \&$ refer_share_channel $=$ copy_ link\&refer_share_form=text; https://item.jd.com/1002711528 5683.html; https://s.taobao.com/search?q=COD\%E5\%8E\%BB\% E9\%99\%A4\%E5\%89\%82\&imgfile $=\&$ js $=1 \&$ stats_click $=$ search radio_all\%3A1\&initiative_id=staobaoz_20210306\&ie $=$ utf 8 . (accessed 24 June 2021)

Huber MM, Korhonen S, Ternes TA et al (2005) Oxidation of pharmaceuticals during water treatment with chlorine dioxide. Water Res 39(15):3607-3617. https://doi.org/10.1016/j.watres.2005.05.040

International Organization for Standardization (ISO) (1983) Water quality-Determination of dissolved oxygen-Iodometric method (ISO 5813: 1983). https://www.iso.org/standard/11959.html. (accessed 24 June 2021)

International Organization for Standardization (ISO) (1989) Water quality-Determination of the chemical oxygen demand (ISO 6060: 1989). https://www.iso.org/standard/12260.html. (accessed 24 June 2021)

International Organization for Standardization (ISO) (2002) Water quality-Determination of the chemical oxygen demand index (STCOD)-Small-scale sealed-tube method (ISO 15705: 2002). https:// www.iso.org/standard/28778.html. (accessed 24 June 2021)

International Organization for Standardization (ISO) (2012) Water quality-Determination of dissolved oxygen-Electrochemical probe method (ISO 5814: 2012). https://www.iso.org/standard/45346. html. (accessed 24 June 2021)

International Organization for Standardization (ISO) (2014) Water quality-Determination of dissolved oxygen-Optical sensor method (ISO 17289: 2014). https://www.iso.org/standard/59515.html. (accessed 24 June 2021)

Kuswandi B, Nitti F, Almeida M et al (2019) Water monitoring using polymer inclusion membranes: a review[J]. Environ Chem Lett 18:18129-18150. https://doi.org/10.1007/s10311-019-00930-9

Lan HM, Guo HX, Deng Y (2011) Interference suppression of nitrite in the determination of dissolved oxygen with iodimetry by adjusting pH. Mod Chem Ind 31(12):93-95. https://doi.org/10.16606/j.cnki. issn0253-4320.2011.12.026

Lavanya M, Shalini S, Suvardhan K et al (2018) Nanotechnology-based water quality management for wastewater treatment. Environ Chem Lett 17:65-121. https://doi.org/10.1007/s10311-018-0778-8

Meng X, Khoso SA, Lyu F et al (2019) Study on the influence and mechanism of sodium chlorate on COD reduction of minerals processing wastewater. Miner 134:1-6. https://doi.org/10.1016/j. mineng.2019.01.009 
Ministry of Ecology and Environment, PRC (MEEC) (1987) Water guality-Determination of dissolved oxyqen-Iodometric method (GB 7489-87). http://www.mee.gov.cn/ywgz/fgbz/bz/bzwb/jcffbz/ 198708/t19870801_68785.shtml. (accessed 24 June 2021)

Ministry of Ecology and Environment, PRC (MEEC) (2011) Discharge standard of water pollutants for phosphate fertilizer industry (GB 15580-2011). http://www.mee.gov.cn/ywgz/fgbz/bz/bzwb/shjbh/ swrwpfbz/201104/t20110420_209475.shtml. (accessed 24 June 2021)

Ministry of Ecology and Environment, PRC (MEEC) (2012) Discharge standard of water pollutants for iron and steel industry (GB 13456-2012). http://www.mee.gov.cn/ywgz/fgbz/bz/bzwb/ shjbh/swrwpfbz/201207/t20120731_234144.shtml. (accessed 24 June 2021)

Ministry of Ecology and Environment, PRC (MEEC) (2017a) Technical requirement and test procedures for rapid COD photometric analyzer (HJ 924-2017). http://english.mee.gov.cn/Resources/ standards/SpecificationsTestProcedures/201801/t20180126_ 430456.shtml. (accessed 24 June 2021)

Ministry of Ecology and Environment, PRC (MEEC) (2017b) Water quality - determination of chemical oxygen demand - potassium dichromate method (HJ 828-2017). http://www.mee.gov.cn/ywgz/ fgbz/bz/bzwb/jcffbz/201704/W020170606398873416325.pdf. (accessed 24 June 2021)

Ministry of Ecology and Environment, PRC (MEEC) (2020a) Notice on further standardizing the environmental management of sewage treatment in cities and towns (parks). In: Water ecological environment management (ed) http://www.mee.gov.cn/xxgk2018/ xxgk/xxgk03/202012/t20201217_813570.html. (accessed 24 June 2021)

Ministry of Ecology and Environment, PRC (MEEC) (2020b) Discharge standard of water pollutants for electronic industry (GB 39731-2020). http://www.mee.gov.cn/ywgz/fgbz/bz/bzwb/shjbh/ swrwpfbz/202012/t20201223_814443.shtml. (accessed 24 June 2021)

Ministry of Ecology and Environment, PRC (MEEC) (2021) The Ministry of Ecology and Environment, PRC reports a case of environmental violations at a sewage treatment plant in Shenmu, Shaanxi Province. http://www.mee.gov.cn/xxgk2018/xxgk/xxgk15/ 202101/t20210122_818381.html. (accessed 24 June 2021)

National Environmental Methods Index (NEMI) (1997) Dissolved oxygen (DO) -Azide modification of Winkler method buret titration. https://www.nemi.gov/methods/method_summary/4786/. (accessed 24 June 2021)

Páramo-Vargas J, Granados SG, Maldonado-Rubio MI et al (2016) Up to $95 \%$ reduction of chemical oxygen demand of slaughterhouse effluents using Fenton and photo-Fenton oxidation. Environ Chem Lett 14:149-154. https://doi.org/10.1007/s10311-015-0534-2

Prince AL (1964) Determination of chloride, hypochlorite, chlorite, chlorate, perchlorate, and chlorine dioxide in composite mixtures. Anal Chem 36(3):613-616. https://doi.org/10.1021/ac60209a017

Sharma VK, Sohn M (2012) Reactivity of chlorine dioxide with amino acids, peptides, and proteins[J]. Environ Chem Lett 10(3):255264. https://doi.org/10.1007/s10311-012-0355-5

Singh S, Maji PK, Lee YS et al (2020) Applications of gaseous chlorine dioxide for antimicrobial food packaging: a review. Environ Chem Lett 19:253-270. https://doi.org/10.1007/s10311-020-01085-8

U.S. Environmental Protection Agency (EPA) (1992) Standard methods for the examination of water and wastewater. https://archive.epa. gov/water/archive/web/html/vms52.html. (accessed 24 June 2021)

U.S. Environmental Protection Agency (EPA) (1993) Method 410.4, Revision 2.0: The determination of chemical oxygen demand by semiAutomated colorimetry. https://www.epa.gov/sites/ production/files/2015-08/documents/method_410-4_1993.pdf. (accessed 24 June 2021)

Una Norma Espanola (UNE) (2002) Water quality. Determination of the chemical oxygen demand (COD). Dichromate method (UNE 77004: 2002). https://www.en.une.org/encuentra-tu-norma/buscatu-norma/norma?c=N0026986. (accessed 24 June 2021)

Yang J, Liu Z, Zeng Z et al (2018) A method for removing persulfate interference in the analysis of the chemical oxygen demand in wastewater. Environ Chem Lett 17:1085-1089. https://doi.org/10. 1007/s10311-018-00832-2

Zhao HJ, Jiang DL, Zhang SQ et al (2004) Development of a direct photoelectrochemical method for determination of chemical oxygen demand. Anal Chem 76:155-160. https://doi.org/10.1021/ ac0302298

Publisher's Note Springer Nature remains neutral with regard to jurisdictional claims in published maps and institutional affiliations. 